\title{
Test of Nucleation Models from Compiled Data
}

\author{
J. Torrent-Burgués * \\ Department of Chemical Engineering, Universitat Politècnica de Catalunya, C/ Colom 1, \\ 08222 Terrassa (Barcelona), Spain
}

Received 17 May 2006; accepted 6 September 2006

\begin{abstract}
Nucleation models have been tested using reported experimental nucleation data in several systems dealing with electrocrystallization from aqueous solutions, and with a wide range of supersaturations or overpotentials. The critical nucleus size has been calculated and the results obtained with the classical and atomistic models have been compared and discussed. In order to compare these values with those occurring in crystallization, the values of the critical nucleus size for several crystallization systems have also been calculated, and then compared and commented.
\end{abstract}

Keywords: nucleation, electrocrystallization, atomistic model, classical models, critical nucleus size.

\section{Introduction}

Nucleation is an important phenomenon which plays a fundamental role in crystal growth and, especially, in precipitation and electrocrystallization, but also in other fields [1]. Nucleation and its control are going to be very important in the synthesis of nanoparticles and nanostructured materials [2-8]. Theories of nucleation have been developed along the last century, from both thermodynamic and kinetic points of view [1, 9-14]. The phenomenon of electrocrystallization has been treated by several authors [15-21] and reviewed recently [22-23]. Experimental analysis of nucleation models presents several problems, joined to the control of the system where nucleation occurs or to the nucleation detection technique. As a consequence, notable dispersion is observed in the reported data. Nucleation models predict certain dependence between the nucleation rate and the supersaturation or overpotential acting in the system.

To test the classical models as well the atomistic model of nucleation, several systems have been selected dealing with electrochemical nucleation. Not enough systems have been tested in the literature with the atomistic model. One of the points that has deserved less attention in the discussions of the different nucleation

\footnotetext{
* Corresponding author. E-mail address: juan.torrent@upc.edu
} 
models is that about the critical nucleus size. In this work this point has been considered and, from the treatment of experimental data, the critical nucleus size has been calculated for different systems. Finally, some discussions are presented.

\section{Revision of nucleation models Classical models}

The classical models use macroscopic magnitudes, as the interfacial tension $\sigma$, and the nucleus size is treated as a continuous value. For a major revision see the references previously cited. In the case of $3 \mathrm{D}$ homogeneous or heterogeneous nucleation, and under the consideration that the surface of the nucleus is related to the power $2 / 3$ of the volume, the following expressions are obtained for the critical nucleus:

$$
\begin{aligned}
& \Delta \mathrm{G}\left(\mathrm{n}^{*}\right)=\mathrm{b} \Omega^{2} \sigma^{3} /\left(\Delta \mu^{2}\right) \mathrm{F}(\theta)=\mathrm{b} \Omega^{2} \sigma^{3} /\left(\mathrm{k}^{2} \mathrm{~T}^{2} \ln ^{2} \beta\right) \mathrm{F}(\theta) \\
& \mathrm{n}^{*}=2 \Delta \mathrm{G}\left(\mathrm{n}^{*}\right) /(\mathrm{kT} \ln \beta) \mathrm{F}(\theta)
\end{aligned}
$$

where $\mathrm{n}^{*}$ : number of particles in the critical nucleus, $\mathrm{b}$ : shape factor, $\Omega$ : molecular volume and $\beta$ : supersaturation ratio $\left(\beta=\mathrm{a} / \mathrm{a}_{\mathrm{sat}}\right)$. The function $\mathrm{F}(\theta)$ takes the value of 1 for homogeneous nucleation and depends on the contact angle, or the adhesion energy between substrate and nucleation phase in the case of heterogeneous nucleation. This function is difficult to establish and usually is neglected in practice. A proposed solution [22b] is to consider $\sigma$ as an average specific interface energy that takes into account the interface energy between nucleus and substrate. Under this assumption when $\mathrm{F}(\theta)=1$, the above expressions can be rewritten as:

$$
\begin{aligned}
& \Delta \mathrm{G}\left(\mathrm{n}^{*}\right)=\mathrm{kTB}_{3 \mathrm{D}} / \mathrm{ln}^{2} \beta \\
& \mathrm{n}^{*}=2 \mathrm{~B}_{3 \mathrm{D}} / \ln ^{3} \beta
\end{aligned}
$$

where

$$
\mathrm{B}_{3 \mathrm{D}}=\mathrm{b} \Omega^{2} \sigma^{3} /(\mathrm{kT})^{3}
$$

The kinetic approach to the nucleation process considers that the nucleus formation proceeds by addition and aggregation of individual particles in a reversible process, where some aggregates redissolve while others growth, and some of them reach the critical size. The nucleation rate takes the form:

$$
\mathrm{J}=\mathrm{Zc}{ }^{*} \mathrm{~b}^{*}
$$

where $\mathrm{Z}$ is the Zeldovich factor, $\mathrm{b}^{*}$ is the probability of a monomer to be incorporated in the critical nucleus, and $\mathrm{c}^{*}$ is the equilibrium concentration of the critical nuclei. This last term can be expressed as $c^{*}=N_{1} \exp \left(-\Delta G^{*} / k T\right)$ where $N_{1}$ is the monomer concentration. For most of the systems, the nucleation rate can be expressed by a general equation [12]: 


$$
\mathrm{J}=\mathrm{J}_{\mathrm{o}} \exp \left[-\Delta \mathrm{G}^{*} /(\mathrm{kT})\right]=\mathrm{J}_{\mathrm{o}} \exp \left[-\mathrm{B}_{3 \mathrm{D}} /\left(\ln ^{2} \beta\right)\right]
$$

where $\mathrm{J}_{\mathrm{o}}$ is a practically supersaturation independent term. Then

$$
\mathrm{B}_{3 \mathrm{D}} \approx-\frac{\mathrm{d} \ln \mathrm{J}}{\mathrm{d}\left(1 / \ln ^{2} \beta\right)}
$$

and the value of $\mathrm{n}^{*}$ can be calculated from eq. (4).

For ionic solutions, if $\beta=S^{v}$, where $v=v_{+}+v_{-}$and $v_{+}$and $v_{-}$. represent the number of cations and anions in the molecular formula, respectively, the previous equations can be rewritten as:

$$
\mathrm{J}=\mathrm{J}_{0} \exp \left[-\mathrm{B}^{\prime}{ }_{3 \mathrm{D}} /\left(\ln ^{2} \mathrm{~S}\right)\right]
$$

where $\quad \mathrm{B}_{3 \mathrm{D}}^{\prime}=\mathrm{B}_{3 \mathrm{D}} / v^{2}$

$$
\begin{aligned}
& \mathrm{B}_{3 \mathrm{D}}^{\prime} \approx-\frac{\mathrm{d} \ln \mathrm{J}}{\mathrm{d}\left(1 / \ln ^{2} \mathrm{~S}\right)} \\
& \mathrm{n}^{*}=2 \mathrm{~B}_{3 \mathrm{D}}^{\prime} /\left(\operatorname{vln}^{3} \mathrm{~S}\right)
\end{aligned}
$$

No considerations on the mononuclear $(\mathrm{MN})$ or the polynuclear $(\mathrm{PN})$ models $[1,11,24-26]$ will be made here since they are not strictly necessary for the target of the work, and otherwise they could complicate excessively the data treatment.

\section{Atomistic model}

In the atomistic model the critical nucleus size is not a continuous function of supersaturation but has a discrete character. Then, there is a supersaturation interval where the size of the critical nucleus is the same. For the nucleation rate we have the following expressions:

$$
\begin{aligned}
& \mathrm{J}=\mathrm{J}_{\mathrm{o}} \exp \left[-\left(\Phi\left(\mathrm{n}^{*}\right)-\mathrm{n}^{*} \Delta \mu\right) / \mathrm{kT}\right] \\
& \Phi\left(\mathrm{n}^{*}\right)-\mathrm{n}^{*} \Delta \mu=\Delta \mathrm{G}\left(\mathrm{n}^{*}\right)
\end{aligned}
$$

In the atomistic model $\Phi\left(\mathrm{n}^{*}\right)$, the excess surface energy, and $\mathrm{n}^{*}$ are constants in a given supersaturation interval and then $\ln J$ depends linearly on $\Delta \mu=\mathrm{kT} \ln \beta$ for each interval $[13,27]$, showing discontinuities when passing from one interval to another. Considering $\mathrm{J}_{\mathrm{o}}$ as a practically supersaturation independent term, we have for each interval:

$$
\frac{d \ln J}{d \ln \beta}
$$


or

$$
\frac{d \ln J}{d \ln S}=v n^{*}
$$

When we deal with electrocrystallization, as $\ln \beta=\mathrm{zF} \eta / \mathrm{RT}$, where $\eta$ is the overpotential, we can write $[1,16,23,27]$ :

$$
\frac{\mathrm{RT} \mathrm{d} \operatorname{lnJ}}{\mathrm{zF} \mathrm{d} \mathrm{\eta}}=\mathrm{n}^{*}
$$

\section{Treatment of data and results}

One of the serious problems concerned with nucleation theories is their experimental test. As can be seen from eq. (7) and eq. (12), nucleation models predict certain dependence between the nucleation rate and supersaturation. In some cases the nucleation rate can be related to the induction time $t_{i}$. The induction time includes the time for nucleation, $t_{n}$, and the time for nucleus growth until a detectable size, $t_{g}$. When a nucleation control exists $t_{n}>>t_{g}$, and then

$$
\mathrm{t}_{\mathrm{i}} \approx \mathrm{t}_{\mathrm{n}} \propto 1 / \mathrm{J}
$$

For a simplicity in the data treatment, it will be assumed that this consideration holds and then, in equations (8), (10), (14), (15) and (16), the term $d \ln J$ can be substituted by $\left(-d \operatorname{lnt}_{\mathrm{i}}\right)$ :

$$
\frac{d \ln t_{i}}{d \ln \beta}=-n^{*}
$$

or

$$
\frac{{\mathrm{d} l n t_{i}}}{\mathrm{~d} \ln S}=-\mathrm{vn}^{*}
$$

and when we deal with electrocrystallization, we can write

$$
\mathrm{RT} \mathrm{d} \mathrm{lnt}_{\mathrm{i}}=-\mathrm{n}^{*}
$$

$\mathrm{zF} \mathrm{d} \eta$

In those systems where the number of nuclei $\mathrm{N}$ was reported for an instantaneous nucleation, it was assumed that $\mathrm{J} \propto \mathrm{N}[1,23]$ and then similar equations to eqs. (14), (15) and (16) were used. For the atomistic model, plots of $\ln Y$ (with Y being $t_{i}$ or $J$ or $N$ ) versus $\ln X$ (with $X$ being $\beta$ or $S$ ), or versus the overpotential $\eta$, were done and from the slope the value of $n^{*}$ was determined. For the classical 
model, plots of $\ln \mathrm{Y}$ versus $1 / \ln ^{2} \mathrm{X}$ were treated and from the slope the value of $\mathrm{n}^{*}$ was determined. These models have been tested from experimental systems dealing with electrocrystallization (Table 1). Some of the reported values have been calculated by the author from original data, but others were reported in the original paper.

\section{Discussion}

The values of the critical nucleus size obtained with both classical and atomistic models (Table 1) indicate that a small or very small critical nucleus is formed, but their values agree. This agreement is not strange since from eq. (8) and eq. (4) of the classical model it is obtained that $\mathrm{n}^{*}=\mathrm{d} \ln \mathrm{J} / \mathrm{d} \ln \beta$, which coincides with eq. (14) of the atomistic model. Small values of the critical nucleus were also compiled by Krumm et al. [33] and by Budevski et al. [22b] for other systems in electrodeposition, and these small values seem to reinforce that the atomistic model is more realistic, and especially at the higher supersaturations which are present in electrocrystallisation. Critical nucleus sizes of zero, which appears in some electrocrystallization systems at high overpotentials, can be explained by the presence of active sites on the electrode surface. The active sites play the role of the critical nucleus [17], and when the necessary overpotential or supersaturation is reached, nucleation occurs at these centres. Nanoscopic structural defects, ions, impurity molecules and foreign nanoparticles in the volume of the old phase or on the substrate surface are examples of such active centres [1]. The data in Table 1 clearly show that the higher values for the critical nucleus size occur at single crystals or at well defined crystalline faces, and at low enough overpotentials (systems $\mathrm{d}, \mathrm{g}, \mathrm{h}, \mathrm{k}$ in Table 1), as a consequence of a lower density of defects in the substrate.

From the plot of $\operatorname{lnt} t_{i}$ vs. $\ln \beta$ it is seen, in several systems, a change in the slope (e.g. $\mathrm{PbSO}_{4}$ in Table 1 and Fig. 1) that according to the atomistic model indicates a change in the critical nucleus size, but in a discrete way. The existence of nucleus sizes more stable than others is predicted by the atomistic models [9, 13]. Taking into consideration the very small determined critical nucleus size, it seems that magnitudes used by the classical models, as the interfacial tension, are without sense or meaning. But, on the other hand, the sizes predicted by the classical models agree with those of the atomistic model. This result seems to justify the formal use of classical models, but the meaning of the magnitudes they use should be revised.

From considerations of the atomistic model [15, 23], when the critical nucleus size changes $\Delta \mathrm{G}\left(\mathrm{n}_{1}{ }^{*}\right)=\Delta \mathrm{G}\left(\mathrm{n}_{2}{ }^{*}\right)$, and according to eq. (13), it is possible to calculate $\Phi\left(\mathrm{n}_{1}{ }^{*}\right)-\Phi\left(\mathrm{n}_{2}{ }^{*}\right)$. When $\mathrm{n}^{*}$ changes from 1 to 0 , the values of $\Phi(1)$ and $\Delta \mathrm{G}(1)$ can be obtained. From the systems and values reported in Table 1, the results shown in Table 2 arise. From the values of $\Phi(1)$ it is seen a certain correlation with the overpotential, being necessary higher overpotentials when the excess surface energy increases. Lower values of $\Phi(1)$ could indicate a strong interaction with the substrate, as in the case of $\mathrm{PbSO}_{4}$ on $\mathrm{Hg} / \mathrm{Pb}$ amalgam. 
Table 1. Critical nucleus size, $n^{*}$, in electrocrystallization, calculated from the classical and atomistic models. $\mathrm{t}_{\mathrm{i}}$ : induction time, $\mathrm{J}$ : nucleation rate, $\mathrm{N}$ : number of nuclei. Supersaturation expressed as potential or overpotential in $\mathrm{V}$, except for $a$ ) and $b$ ) where the values between ( ) are expressed as $\mathrm{S}=\mathrm{a} / \mathrm{a}_{\mathrm{sat}}=\mathrm{IAP} / \mathrm{K}_{\mathrm{SP}}$; $\left.\mathrm{h}-\mathrm{q}\right)$ : values reported in the original paper.

\begin{tabular}{|c|c|c|c|c|}
\hline System & Supersat. & $\mathrm{n}^{*}$ clas. & $\mathrm{n}^{*}$ atom. & original data and refer. \\
\hline a) $\mathrm{PbCl}_{2}$ on $\mathrm{Hg} / \mathrm{Pb}$ & $\begin{array}{l}0.067-0.117 \\
(190-6720)\end{array}$ & $2-0$ & 1 & $\mathrm{t}_{\mathrm{i}} ; 28$ \\
\hline \multirow[t]{3}{*}{ b) $\mathrm{PbSO}_{4}$ on $\mathrm{Hg} / \mathrm{Pb}$} & $\begin{array}{l}0.025-0.100 \\
(7-2450)\end{array}$ & $2-0$ & & $\mathrm{t}_{\mathrm{i}} ; 28$ \\
\hline & $\begin{array}{l}0.025-0.060 \\
(7-110)\end{array}$ & & 1 & \\
\hline & $\begin{array}{l}0.060-0.100 \\
(110-2450)\end{array}$ & & 0 & \\
\hline c) $\mathrm{AgO}$ on $\mathrm{Ag}$ & $E=0.63-0.74$ & & 1 & $\mathrm{t}_{\mathrm{i}} ; 29$ \\
\hline d) $\mathrm{Hg}$ on $\mathrm{Pt}$ & $\begin{array}{r}\eta=0.084-0.094 \\
0.094-0.106\end{array}$ & & $\begin{array}{c}10 \\
6\end{array}$ & $\mathrm{~J} ; 30$ \\
\hline e) $\mathrm{Sn}$ on $\mathrm{C}$ & $\eta=0.160-0.410$ & & $1-0$ & $\mathrm{~N} ; 31$ \\
\hline f) $\mathrm{Zn}$ on $\mathrm{C}$ & $-E=1.35-1.70$ & & $1-0$ & $\mathrm{~N} ; 32$ \\
\hline g) $\mathrm{Cd}$ on $\mathrm{Si}(111)$ & $\begin{array}{r}\eta=0.015-0.021 \\
0.474-0.520\end{array}$ & & $\begin{array}{c}6 \\
1-0\end{array}$ & $\mathrm{~J} ; 33$ \\
\hline h) $\mathrm{Tl}$ on $\mathrm{Si}(111)$ & $\eta=0.003-0.007$ & & 18 & $\mathrm{~J} ; 33$ \\
\hline i) $\mathrm{Rh}$ on $\mathrm{Au}$ & $E=0.2-0$ & & $1-0$ & $\mathrm{~J} ; 34$ \\
\hline j) $\mathrm{Ag}$ on $\mathrm{C}$ & $\begin{array}{l}\eta=0.09-0.24 \\
\eta=0.09-0.16 \\
\eta=0.16-0.24\end{array}$ & $3-1$ & $\begin{array}{l}1 \\
0\end{array}$ & $\mathrm{~J} ; 35$ \\
\hline k) $\mathrm{Cd}$ on $\mathrm{Cd}(0001)$ & $\eta=0.015-0.045$ & & 5 & $\mathrm{~J} ; 36$ \\
\hline 1) $\mathrm{Ag}$ on $\mathrm{Si}$ & $-E=0.8-0.9$ & & $1-0$ & $\mathrm{~J} ; 37$ \\
\hline $\mathrm{Ag}$ on $\mathrm{C}$ & $-E=0.7-0.9$ & & $1-0$ & \\
\hline m) $\mathrm{Zn}$ on $\mathrm{HOPG}$ & $\eta=0.22-0.37$ & & 1 & $\mathrm{~J} ; 38$ \\
\hline n) $\mathrm{Bi}$ on $\mathrm{C}$ & $-E=0.1-0.35$ & & 0 & $\mathrm{~J} ; 39$ \\
\hline o) Pt on W & $-E=0.54-0.76$ & & 0 & $\mathrm{~J} ; 40$ \\
\hline p) Pt on $\mathrm{Ti}$ & $-E=0.56-0.68$ & & 0 & $\mathrm{~J} ; 41$ \\
\hline q) Rh on PG & $-E=0.17-0.30$ & & 0 & $\mathrm{~J} ; 42$ \\
\hline r) $\mathrm{Ni}$ on $\mathrm{C}$ & $-E=0.93-0.98$ & & $1-0$ & $\mathrm{~J} ; 43$ \\
\hline Co on $\mathrm{C}$ & $-E=0.83-0.88$ & & $1-0$ & \\
\hline s) $\mathrm{Co}$ on $\mathrm{C}$ & $-E=1.2-1.5$ & & 0 & $\mathrm{~J} ; 44$ \\
\hline
\end{tabular}




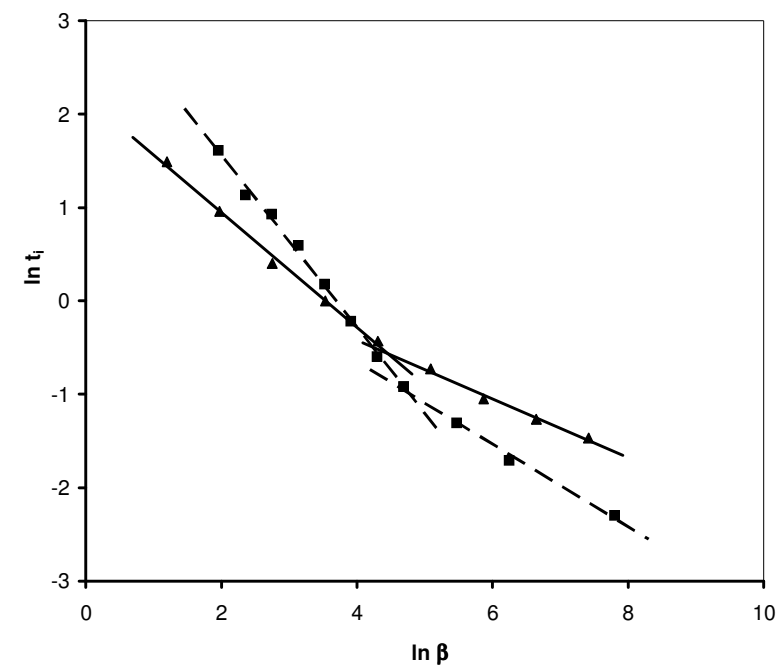

Figure 1. Plot of $\operatorname{lnt}_{\mathrm{i}}$ versus $\ln \beta$ for electrocrystallization of $\mathrm{PbSO}_{4}$ on $\mathrm{Hg} / \mathrm{Pb}$ amalgam, from: -- --) $0.5 \mathrm{M} \mathrm{H}_{2} \mathrm{SO}_{4}$ solution, - $\left.\longrightarrow\right) 0.04 \mathrm{M} \mathrm{H}_{2} \mathrm{SO}_{4}$ solution.

Table 2. Values of $\Phi\left(\mathrm{n}_{1}{ }^{*}\right)-\Phi\left(\mathrm{n}_{2}{ }^{*}\right), \Phi(1)$ and $\Delta \mathrm{G}(1)$ for some systems: (a-c) presented in Table 1, and (d-f) reported in [23]. Overpotential at the point of change of $n^{*}, \eta$, expressed in $\mathrm{V}$.

$\begin{array}{lllll}\text { System } & \Phi\left(\mathrm{n}_{1}{ }^{*}\right)-\Phi\left(\mathrm{n}_{2}{ }^{*}\right) 10^{20} / \mathrm{J} & \Phi(1) 10^{20} / \mathrm{J} & \Delta \mathrm{G}(1) 10^{20} / \mathrm{J} & \eta / \mathrm{V}\end{array} \quad$ ref.

Table 1

\begin{tabular}{llllll}
\hline a) $\mathrm{PbSO}_{4}$ on $\mathrm{Hg} / \mathrm{Pb}$ & $\Phi(1)-\Phi(0)=1.9$ & 1.9 & $1.1-0$ & 0.060 & $\mathrm{~b}$ \\
b) $\mathrm{Hg}$ on $\mathrm{Pt}$ & $\Phi(10)-\Phi(6)=6.0$ & & & 0.094 & $\mathrm{~d}$ \\
c) $\mathrm{Ag}$ on $\mathrm{C}$ & $\Phi(1)-\Phi(0)=2.6$ & 2.6 & $1.1-0$ & 0.160 & $\mathrm{j}$ \\
d) $\mathrm{Ag}$ on $\mathrm{Pt}$ & $\Phi(1)-\Phi(0)=3.8$ & 3.8 & $0.6-0$ & 0.240 & \\
& & & & & \\
e) $\mathrm{Cu}$ on $\mathrm{Pd}$ & $\Phi(1)-\Phi(0)=2.6$ & 2.6 & $0.9-0$ & 0.082 \\
f) $\mathrm{Hg}$ on $\mathrm{C}$ & $\Phi(1)-\Phi(0)=7.7$ & 7.7 & $0.7-0$ & 0.242
\end{tabular}

Nucleation models can also be tested from crystallization in supersaturated solutions. In this case, homogeneous nucleation is possible, but the presence of impurities and surfaces may introduce a certain degree of heterogeneous character. Table 3 presents the values of the critical nucleus size calculated for several aqueous solutions, from soluble to insoluble substances and from low to high supersaturations. Most of these values were calculated by the author from the original data. Equations reported in sections 2 and 3 for the classical and atomistic models were used. 
Table 3. Critical nucleus size, $n^{*}$, in crystallization from aqueous solution, calculated with the classical and atomistic models. Supersaturation expressed as $\mathrm{S}$. $\mathrm{t}_{\mathrm{i}}$ : induction time, J: nucleation rate, $\mathrm{N}$ : number of nuclei; $\mathrm{t}$ ): values reported in the original paper.

\begin{tabular}{|c|c|c|c|c|}
\hline System & Supersat. & $\mathrm{n}^{*}$ clas. & $\mathrm{n}^{*}$ atom. & original data and refer \\
\hline a) $\operatorname{ADP} 25^{\circ} \mathrm{C}$ & $1.40-1.80$ & $8-2$ & 3 & $\mathrm{t}_{\mathrm{i}} ; 45$ \\
\hline b) $\mathrm{KDP} 30^{\circ} \mathrm{C}$ & $1.58-1.70$ & $24-16$ & 14 & $\mathrm{t}_{\mathrm{i}} ; 46$ \\
\hline c) $\mathrm{K}_{2} \mathrm{C}_{2} \mathrm{O}_{4} 25^{\circ} \mathrm{C}$ & $1.12-1.18$ & & 14 & $\mathrm{t}_{\mathrm{i}} ; 11$ \\
\hline d) $\mathrm{K}_{2} \mathrm{Cr}_{2} \mathrm{O}_{7} 25^{\circ} \mathrm{C}$ & $11.8-17.8$ & $3-2$ & 2 & $\mathrm{~J} ; 11$ \\
\hline \multirow[t]{3}{*}{ e) $\mathrm{KAl}\left(\mathrm{SO}_{4}\right)_{2} 15^{\circ} \mathrm{C}$} & $1.41-3.31$ & $5-0$ & & $\mathrm{t}_{\mathrm{i}} ; 12$ \\
\hline & $1.41-1.62$ & & 4 & \\
\hline & $1.62-3.31$ & & 1 & \\
\hline \multirow[t]{3}{*}{ f) $\mathrm{CaCO}_{3} 25^{\circ} \mathrm{C}$} & $19.0-50.1$ & $4-2$ & & $\mathrm{t}_{\mathrm{i}} ; 12$ \\
\hline & $6.3-10.7$ & & 3 & \\
\hline & $10.7-50.1$ & & 2 & \\
\hline \multirow[t]{3}{*}{ g) $\mathrm{CaCO}_{3} 25^{\circ} \mathrm{C}$} & $3.60-8.25$ & $7-3$ & & $\mathrm{t}_{\mathrm{i}} ; 47$ \\
\hline & $3.60-4.47$ & & 8 & \\
\hline & $4.47-8.25$ & & 2 & \\
\hline h) $\mathrm{CaCO}_{3} 25^{\circ} \mathrm{C}$ & $2.60-4.73$ & $14-3$ & & $\mathrm{t}_{\mathrm{i}} ; 25$ \\
\hline i) $\mathrm{SrWO}_{4} 25^{\circ} \mathrm{C}$ & $6.31-10.0$ & $7-3$ & & $\mathrm{t}_{\mathrm{i}} ; 12$ \\
\hline j) $\mathrm{SrSO}_{4} 25^{\circ} \mathrm{C}$ & $250-790$ & & 2 & $\mathrm{t}_{\mathrm{i}} ; 12$ \\
\hline k) $\mathrm{BaSO}_{4} 25^{\circ} \mathrm{C}$ & $4.5-11.0$ & $8-2$ & 2 & $\mathrm{t}_{\mathrm{i}} ; 48$ \\
\hline 1) $\mathrm{CaF}_{2} 23^{\circ} \mathrm{C}$ & $12.2-20.1$ & $5-3$ & 2 & $\mathrm{t}_{\mathrm{i}} ; 49$ \\
\hline m) $\mathrm{KCl} 25^{\circ} \mathrm{C}$ & $1.05-1.16$ & & 6 & $\mathrm{~J} ; 50$ \\
\hline n) $\mathrm{BaCrO}_{4} 22^{\circ} \mathrm{C}$ & $7-700$ & & 1 & $\mathrm{t}_{\mathrm{i}} ; 51$ \\
\hline o) $\mathrm{BaWO}_{4} 25^{\circ} \mathrm{C}$ & $251.2-1000$ & & 5 & $\mathrm{~N} ; 52$ \\
\hline \multirow[t]{2}{*}{ p) $\mathrm{PbSeO}_{4} 25^{\circ} \mathrm{C}$} & $5.0-20.0$ & & 4 & $\mathrm{~N} ; 52$ \\
\hline & $20.0-79.4$ & & 1 & \\
\hline \multirow[t]{2}{*}{ q) $\mathrm{T} 1 \mathrm{Br} 25^{\circ} \mathrm{C}$} & $1.26-25.1$ & & 2 & $\mathrm{~N} ; 52$ \\
\hline & $25.1-158.5$ & & 1 & \\
\hline r) lysozyme $25^{\circ} \mathrm{C}$ & $6-25$ & $3-1$ & & $\mathrm{t}_{\mathrm{i}} ; 53$ \\
\hline \multirow[t]{2}{*}{ in $0.6 \mathrm{M} \mathrm{NaCl}$} & $6-11.8$ & & 5 & \\
\hline & $11.8-25$ & & 2 & \\
\hline s) STA $25^{\circ} \mathrm{C}$ & $3-6$ & $4-1$ & & $\mathrm{t}_{\mathrm{i}} ; 53$ \\
\hline \multirow[t]{2}{*}{ in $5 \mathrm{M} \mathrm{LiCl}$} & $3-4.3$ & & 5 & \\
\hline & $4.3-6$ & & 3 & \\
\hline t) urea $25^{\circ} \mathrm{C}$ & $1.1-1.35$ & $7-0$ & & $\mathrm{t}_{\mathrm{i}} ; 54$ \\
\hline $31{ }^{\circ} \mathrm{C}$ & $1.1-1.35$ & $22-1$ & & \\
\hline
\end{tabular}


Table 3 shows that small values of the critical nucleus size also occur in nucleation in solution, but they are usually bigger than those obtained in electrocrystallization. The bigger values of $n^{*}$ occur for more soluble substances and at lower supersaturations. The small values of $\mathrm{n}^{*}$ obtained in electrocrystallization (Table 1) are due to the higher supersaturations usually attained in this case and to the heterogeneous character introduced by the electrode surface, with the presence of defects.

According to the atomistic model, some substances show several linear segments in the plot of $\ln \mathrm{J}$, or $\ln \mathrm{t}_{\mathrm{i}}$, versus $\ln \mathrm{S}$ (substances e-g and p-s in Table 3 ). When a change in the linear slope occurs, values of $\Phi\left(\mathrm{n}_{1}{ }^{*}\right)-\Phi\left(\mathrm{n}_{2}{ }^{*}\right)$ can be calculated, and they are reported in Table 4. These values are of the same order of magnitude than those obtained in electrocrystallization (Table 2). It is seen that the value of $\Phi(4)-\Phi(1)$ for $\mathrm{KAl}\left(\mathrm{SO}_{4}\right)_{2}$ is very low, specially when it is compared with that of $\mathrm{PbSeO}_{4}$. Due to the connection between the excess surface energy, of the atomistic model, and the surface tension, of the classical models, this low value can by related to the low value of the surface tension reported for this system $(\sigma=2.5 \mathrm{mN}$ $\left.\mathrm{m}^{-1}[12]\right)$.

Finally, we can conclude that the atomistic model can be applied to the nucleation phenomenon, both for crystallization and electrocrystallization systems, and that small values for the critical nucleus size are obtained. These values are lower for electrocrystallization systems due to the attained supersaturations are higher and also due to the presence of defects in the electrode surface.

Table 4. Values of $\Phi\left(\mathrm{n}_{1}{ }^{*}\right)-\Phi\left(\mathrm{n}_{2}{ }^{*}\right), \Phi(1)$ for some systems presented in Table 3 (e-g, p-s). Supersaturation, at the point of change of $n^{*}$, expressed as $\mathrm{S}$.

\begin{tabular}{lccc}
\hline System & $\Phi\left(\mathrm{n}_{1}{ }^{*}\right)-\Phi\left(\mathrm{n}_{2}{ }^{*}\right) 10^{20} / \mathrm{J}$ & Supersat. & ref. Table 3 \\
\hline $\mathrm{KAl}_{\left(\mathrm{SO}_{4}\right)_{2}}$ & $\Phi(4)-\Phi(1)=2.3$ & 1.62 & $\mathrm{e}$ \\
$\mathrm{CaCO}_{3}$ & $\Phi(3)-\Phi(2)=2.0$ & 10.7 & $\mathrm{f}$ \\
$\mathrm{CaCO}_{3}$ & $\Phi(8)-\Phi(2)=7.4$ & 4.47 & $\mathrm{p}$ \\
$\mathrm{PbSeO}_{4}$ & $\Phi(4)-\Phi(1)=7.4$ & 20 & $\mathrm{q}$ \\
$\mathrm{TlBr}$ & $\Phi(2)-\Phi(1)=2.7$ & 25.1 & $\mathrm{r}$ \\
lysozyme & $\Phi(5)-\Phi(2)=3.0$ & 11.8 & $\mathrm{~s}$ \\
STA & $\Phi(5)-\Phi(3)=1.2$ & 4.26 & \\
\hline
\end{tabular}

\section{References}

1. D. Kashchiev, Nucleation. Basic Theory with Applications, ButterworthsHeinemann, Oxford, 2000.

2. S. Auer, D. Frenkel, Nature 413 (2001) 711.

3. K.J. Klabunde, Nanoscale Materials in Chemistry, Wiley Interscience, N.Y., 2001.

4. H. Liu, F. Favier, K. Ng, M.P. Zach, R.M. Penner, Electrochim. Acta 47 (2001) 671 . 
5. M.P. Pileni, Cryst. Res. Technol. 33 (1998) 1155.

6. R. Rodríguez-Clemente, A. López, J. Gómez, J. Torrent-Burgués, V.M. Castaño, J. European Ceramic Soc. 18 (1998) 1351.

7. J. Torrent-Burgués, J. Gómez, A. López, R. Rodríguez-Clemente, Crys. Res. Tech. 34 (1999) 757.

8. J. Torrent-Burgués, R. Rodríguez-Clemente, Crys. Res. Tech. 36 (2001) 1075.

9. B. Lewis, Chap. 2 in Crystal Growth, B.R. Pamplin, Ed., Pergamon Press, Oxford, 1980.

10. I.V. Markov, Crystal Growth for Beginners, World Scientific, Singapore, 1995.

11. K. Sangwal, M. Jakubczyk, Chap. 3 in Elementary Crystal Growth, K. Sangwal, Ed., Saan Publishers, Lublin, 1994.

12. O. Söhnel, J. Garside, Precipitation, Butterworth-Heinemann, Oxford, 1992.

13. S. Stoyanov, Nucleation theory for high and low supersaturations, Current Topics in Materials Science, vol. 3, E. Kaldis, Ed., North-Holland Publishing Company, Amsterdam, 1979.

14. S. Toschev, Chap. 1 in Crystal Growth: An Introduction, P. Hartman, Ed., North-Holland Publishing Company, Amsterdam, 1973.

15. A. Milchev, Contemporary Physics 32 (1991) 321.

16. A. Milchev, S. Stoyanov, J. Electroanal. Chem. 72 (1976) 33.

17. A. Milchev, S. Stoyanov, R. Kaischew, Thin Solid Films 22 (1974) 255.

18. E. Bosco, S.K. Rangarajan, J. Electroanal. Chem. 134 (1982) 213.

19. G. Gunawardena, G. Hills, I. Montenegro, B. Scharifker, J. Electroanal. Chem. 138 (1982) 225.

20. A. Milchev, R. Lacmann, J. Cryst. Growth 110 (1991) 919.

21. A. Milchev, I. Montenegro, J. Electroanal. Chem. 333 (1992) 93.

22. E. Budevski, G. Staikov, W.J. Lorenz, (a) Electrochim. Acta 45 (2000) 2559;

(b) Electrochemical Phase Formation and Growth, VCH, Weinheim, 1996.

23. A. Milchev, Electrocrystallization. Fundamentals of Nucleation and Growth, Kluwer Academic Publishers, Boston, 2002.

24. D. Kashchiev, D. Verdoes, G.M. van Rosmalen, J. Crystal Growth 110 (1991) 373.

25. D. Verdoes, D. Kashchiev, G.M. van Rosmalen, J. Crystal Growth 118 (1992) 401.

26. K. Sangwal, W. Polak, Crys. Res. Tech. 32 (1997) 509.

27. D. Kashchiev, J. Chem. Phys. 76 (1982) 5098.

28. J. Torrent, R. Rodríguez, J.H. Sluyters, J. Crystal Growth 131 (1993) 115.

29. T.P. Dirkse, Electrochim. Acta 35 (1990) 1445.

30. S. Toschev, I.V. Markov, Ber. Bunsengen. Physik Chem. 73 (1969) 184.

31. E. Guaus, J. Torrent-Burgues, Portug. Electrochim. Acta 19 (2001) 247.

32. P.J. Sonneveld, W. Visscher, E. Barendrecht, Electrochim. Acta 37 (1992) 1199.

33. R. Krumm, B. Guel, C. Schmitz, G. Staikov, Electrohim. Acta 45 (2000) 3255. 
34. M. Arbib, B. Zhang, V. Lazarov, D. Stoychev, A. Milchev, C. BuessHerman, J. Electroanal. Chem. 510 (2001) 67.

35. A. Milchev, E. Vassileva, J. Electroanal. Chem. 107 (1980) 337.

36. V. Bostanov, E. Mladenova, D. Kashchiev, J. Electroanal. Chem. 481 (2000) 7.

37. K. Marquez, G. Staikov, J.W. Schultze, Electrochim. Acta 48 (2003) 875.

38. A.E. Alvarez, D.R. Salinas, J. Electroanal. Chem. 566 (2004) 393.

39. M. Yang, Z. Hu, J. Electroanal. Chem. 583 (2005) 46.

40. A. Kelaidopoulou, G. Kokkinidis, A. Milchev, J. Electroanal. Chem. 444 (1998) 195.

41. A. Milchev, D. Stoychev, V. Lazarov, A. Papoutsis, G. Kokkinidis, J. Crystal Growth 226 (2001) 138.

42. O. Brylev, L. Roué, D. Bélanger, J. Electroanal. Chem. 581 (2005) 22.

43. A.N. Correia, S.A.S. Machado, L.A. Avaca, J. Electroanal. Chem. 488 (2000) 110.

44. M.E. Hyde, O.V. Klymenko, R.G. Compton, J. Electroanal. Chem. 534 (2002) 13.

45. S. Nagalingam, S. Vasudevan, P. Ramasamy, S. Laddha, Krist. Technik 15 (1980) 1151.

46. B.K. Paul, M.S. Joshi, J. Phys. D: Appl. Phys. 9 (1976) 1253.

47. J. Gomez-Morales, J. Torrent-Burgués, R. Rodriguez-Clemente, J. Crystal Growth 169 (1996) 331.

48. M.C. van der Leeden, D. Kashchiev, G.M. van Rosmalen, J. Colloid Interface Sci. 152 (1992) 338.

49. H.E. Lundager Madsen, J. Crystal Growth 80 (1987) 371.

50. I. Liszi, T. Blickle, J. Liszi, Crys. Res. Tech. 20 (1985) 1309.

51. A. Packter, A. Alleem, Crys. Res. Tech. 16 (1981) 33.

52. A.E. Nielsen, O. Söhnel, J. Crystal Growth 11 (1971) 233.

53. A.M. Kulkarni, C.F. Zukoski, Langmuir 18 (2002) 3090.

54. S. Boomadevi, R. Dhanasekaran, P. Ramasamy, Cryst. Res. Technol. 37 (2002) 159. 